
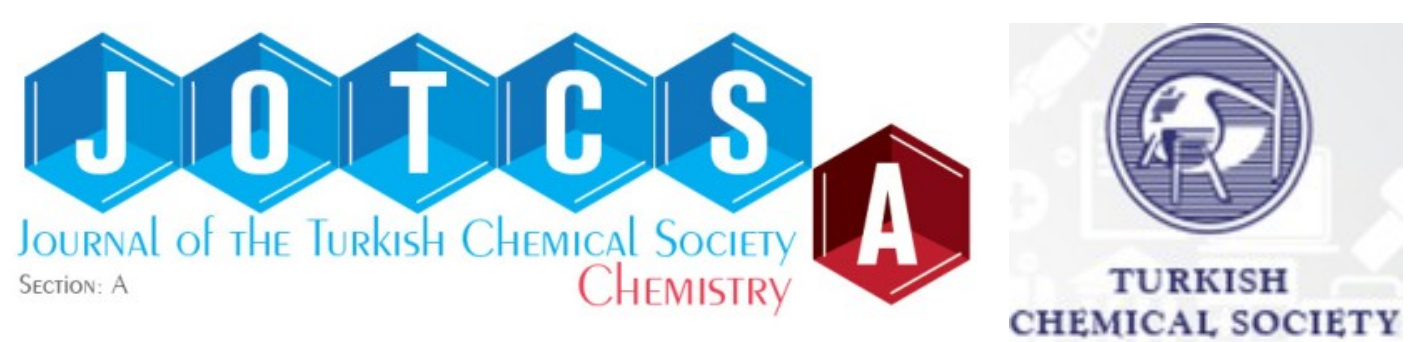

\title{
Role of Initiator Structure on Thiol-Ene Polymerization: A Comprehensive Theoretical Study
}

\author{
Isa Degirmenci ${ }^{1}$ \\ ${ }^{1}$ Ondokuz Mayıs University, Chemical Engineering Department, Samsun, 55139, Turkey
}

\begin{abstract}
The effect of initiator nature on thiol-ene polymerization was elaborated in this work with two initiators, four thiols, and eight monomers by utilizing the M06-2X/6-31++G(d,p) level of theory. For this purpose, a comparative investigation was carried out by modeling hydrogen abstraction from thiols $\left(\mathrm{k}_{\mathrm{HA}}\right)$ and addition reaction to monomers $\left(\mathrm{k}_{\mathrm{i}}\right)$, which is considered a side reaction. It was confirmed that the 2,2-dimethoxy-2-phenylacetophenone (DMPA) initiator is a suitable thiol-ene initiator except for the polymerization of electron-deficient or conjugated monomers. It was determined that the azobis(isobutyronitrile) (AIBN) initiator could not give a homogeneous thiol-ene product regardless of the monomer structure. However, it has been found that aromatic thiols should be used to obtain relatively better results with this initiator.
\end{abstract}

Keywords: Thiol-ene polymerization; density functional theory; reaction kinetics; structure-reactivity relationships.

Submitted: October 01, 2021. Accepted: December 28, 2021.

Cite this: Degirmenci I. Role of Initiator Structure on Thiol-Ene Polymerization: A Comprehensive Theoretical Study. JOTCSA. 2022;9(1):149-62.

DOI: https://doi.org/10.18596/jotcsa.1003469.

*Corresponding author. E-mail: isa.degirmenci@omu.edu.tr

\section{INTRODUCTION}

Thiol-ene reaction has attracted attention in the polymer field due to its unique mechanism, which combines the advantages of classical radical and step-growth polymerizations as a radical stepgrowth procedure (1-3). It also has a "click chemistry" feature (3) as it exhibits properties such as being fast, solvent-free, insensitive to oxygen, showing late gel points, with a high yield (4), not forming by-products, forming a uniform polymer structure, and giving products with a narrow glassy transition temperature (3). Thiolene polymerization was first used on surface coatings and films by photo-curable polymers and resins (5). Today, there are many applications from electro-optical materials (6) to dendrimers (7) and from drug carriers (8) to microfluidic devices (9-11).
Many experimental and theoretical studies have focused on the elaboration of steps of thiol-ene polymerization and factors affecting the process (12), such as the effect of solvent medium (13$15)$, the influence of substrate $(12,16)$, or thiol reactivity (17-19). It was demonstrated that the main drawing force for the thiol-ene polymerization is the rate ratios for propagation and chain transfer reactions $\left(k_{p} / k_{c t}\right)(12)$. However, the literature studies have shown that one of the factors affecting the polymerization processes is the electronic structure of the initiator. Experimental and theoretical studies on this subject are limited $(20,21)$. As depicted in Scheme 1, one of the side reactions is radical initiator addition to alkene functionality, leading to classical free radical initiation of homopolymerization. Recombination of initiator radicals, disulfide formations, and 
termination by the combination of carbon-centered radicals are other possible side reactions. This study basically focused on the initiation of homopolymerization since this side reaction can consume one of the thiol-ene polymerization reactants. Our previous study has given clues

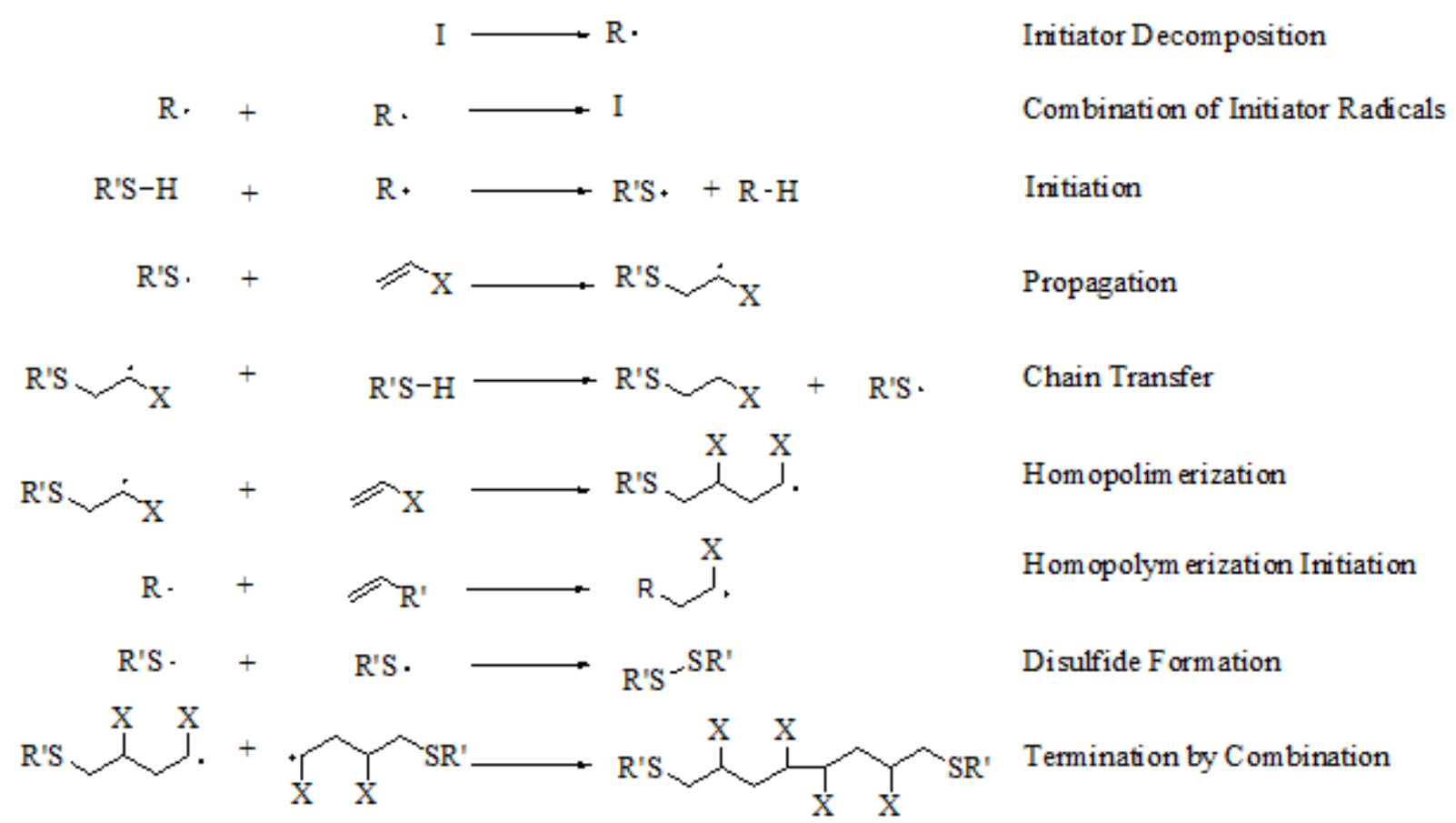

Scheme 1: List of possible reactions during thiol-ene polymerization (22).

Hydrogen abstraction from thiols by initiator radicals is the critical step for initiating thiol-ene polymerization. However, initiator radicals can also attack alkene $\mathrm{C}=\mathrm{C}$ double bond, which initiates classical radical polymerization and is considered a side reaction. Therefore, the reactivity analysis of about this point by investigating a limited number of thiol and alkene functionality (21). In this study, elaboration of initiator performance was extended a larger reaction sets with eight alkenes, four thiols, and two different initiators.

\author{
Initiator Decomposition \\ Combination of Initiator Radicals \\ Initiation \\ Propagation \\ Chain Transfer \\ Hom opolim erization \\ Hom opolym erization Initiation \\ Disulfide Formation
}

radicals generated from azobis(isobutyronitrile) (AIBN) as a classical radical polymerization initiator and 2,2-dimethoxy-2-phenylacetophenone (DMPA) as a thiol-ene polymerization initiator has a crucial role in investigating the efficiency of an initiator for an effective thiol-ene polymerization. 


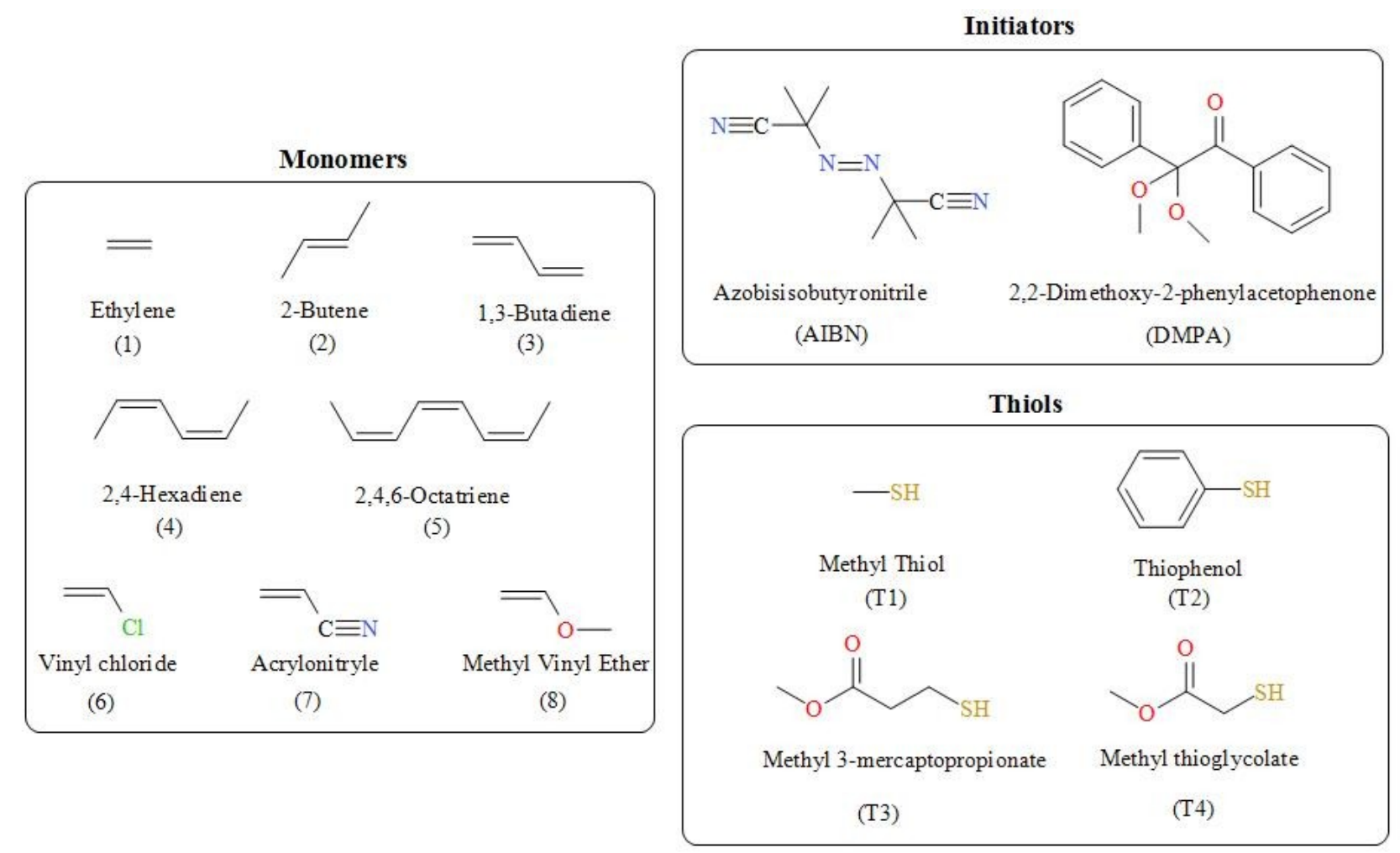

Scheme 2: Chemical structures of monomers, thiols, and initiators investigated in this study.

Methyl thiol (T1), thiophenol (T2), methyl 3mercaptopropionate (T3), and methyl thioglycolate (T4) were used to analyze the effect of thiol functionality. Moreover, eight alkenes were tested due to their different electronic natures, from electron-deficient to electron-rich or conjugated structures, to investigate thiyl radical attacks to monomers, which gives by-products.

\section{METHODOLOGY}

Quantum chemical calculations were carried out by using the Gaussian 16 program package (23). All geometry optimizations, frequencies, and energies were calculated by using M06-2X functional (24). M06-2X/6-31++G(d,p) level of theory has been performed successfully to model thiol-ene polymerization $(15,17)$. Therefore, this level of theory is preferred to model the performance of initiators. The rate constants were predicted using the transition state theory mentioned in the literature (25). The tunneling ( $\mathrm{k}$ ) coefficient was calculated based on the Wigner approximation, given in the following equation $(26,27)$.

$$
\kappa(T)=1+\frac{1}{24}\left|\frac{h \omega^{\ddagger}}{k_{B} T}\right|^{2}
$$

Where, $h$ is Planck's constant $\left(6.6260755 \times 10^{-34}\right.$ J.s), $\omega^{\ddagger}$ is the imaginary frequency, $k_{B}$ is the
Boltzmann's constant $\left(1.380658 \times 10^{-23} \mathrm{~J} . \mathrm{K}^{-1}\right)$, and $\mathrm{T}$ is the temperature $(298.15 \mathrm{~K})$. Moreover, the stability of concerned radicals was expressed by the standard radical stabilization energies (RSE) $(28,29)$.

\section{RESULTS AND DISCUSSION}

Thiol-ene reaction has appeared in literature since 1905 (30). Many experimental (12,31-36) or theoretical $(15-17,19,21)$ studies have been carried out to elucidate the mechanism of thiol-ene polymerization. However, limited studies have focused on the role of the initiator on polymerization involving thiol-ene reactions (20$22,37,38)$. For the first time, a comprehensive investigation was carried out by application of quantum chemical tools in this study.

It was elaborated that whether azobis(isobutyronitrile) (AIBN) and 2,2-dimethoxy2-phenylacetophenone (DMPA) give side reactions in thiol-ene polymerization. Exposure to light or heat leads to the decomposition of these initiators to form radicalic species. Since the polymerization reactions are performed as based on the reactivity of the radicals formed, the decomposition step of the initiators was not modeled by quantum chemical methods. What is expected from the radicals formed is that they initiate thiol-ene polymerization by abstracting the hydrogen atom 
from thiols. Otherwise, the initiator radical can give a side reaction by attacking the monomer effectively. This possibility reduces the efficiency of the thiol-ene polymerization.

\section{Hydrogen Abstraction from Thiols}

Application of AIBN as the initiator produces 2cyano-2-propyl radical $\left(\mathrm{NC}\left(\mathrm{CH}_{3}\right)_{2} \mathrm{C} \bullet\right)$. On the other hand, when DMPA is used as the initiator, two different radicals are formed in the first place, the benzoyl and dimethoxy radicals. While the benzoyl radical $\left(\mathrm{C}_{6} \mathrm{H}_{5} \mathrm{CO} \bullet\right)$ is stable, the other radical is unstable and undergoes further decomposition to yield methyl radical $\left(\mathrm{CH}_{3} \bullet\right)$ and methyl benzoate (39). For this reason, when examining the reactivity of DMPA, the reactions of $\mathrm{CH}_{3} \bullet$ and $\mathrm{C}_{6} \mathrm{H}_{5} \mathrm{CO} \bullet$ radicals have to be taken into account.
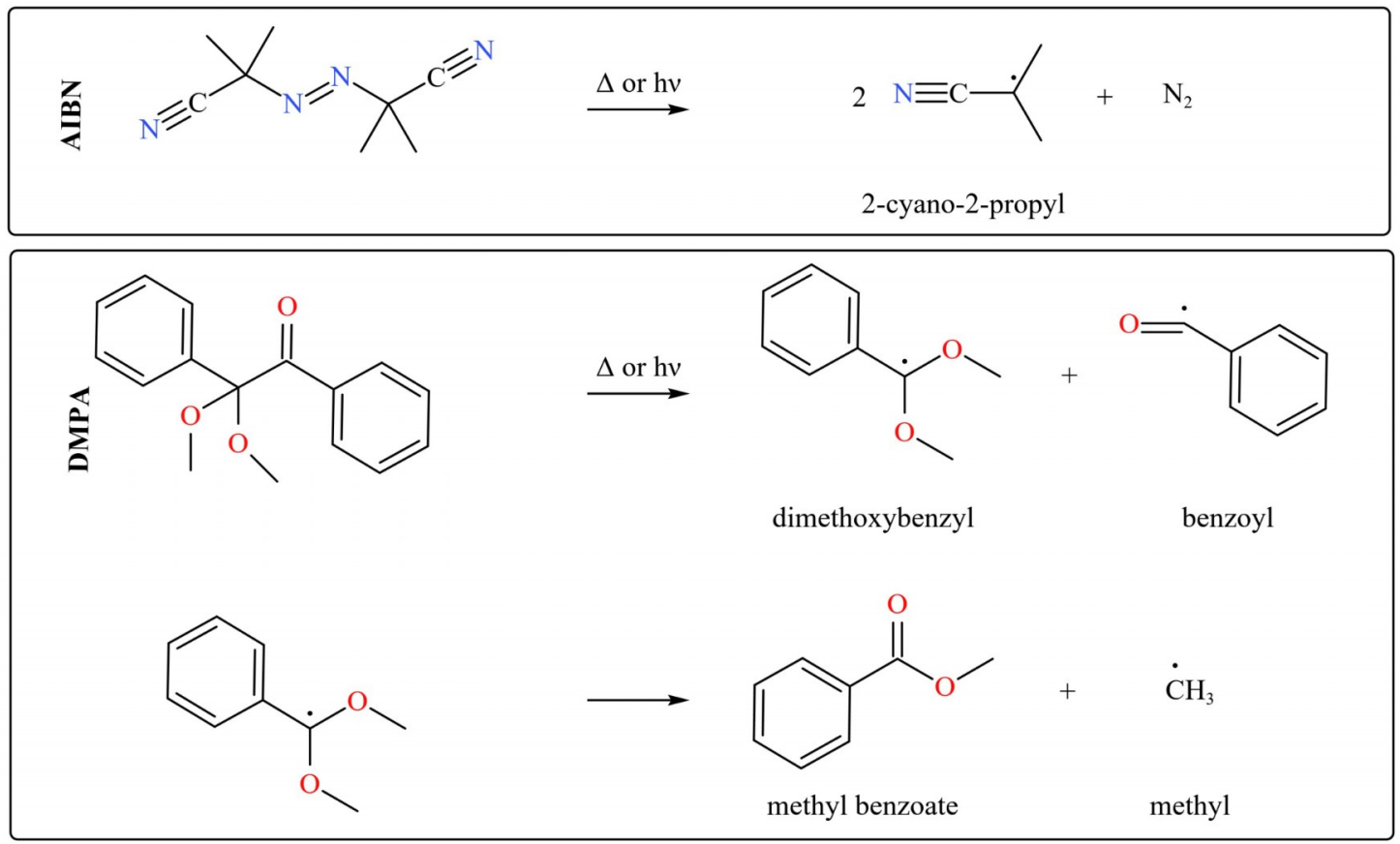

Scheme 3: Radicals formed from the initiators.

Hydrogen abstraction reactions of the $\mathrm{NC}\left(\mathrm{CH}_{3}\right)_{2} \mathrm{C} \bullet$ radical are significantly less exothermic than the reaction of the other radicals (Table $\mathrm{S} 1$ ). This is because $\mathrm{NC}\left(\mathrm{CH}_{3}\right)_{2} \mathrm{C}$ - radical is much more stable than the others (21). For example, while the enthalpy of the reaction with thiophenol is -45.90 $\mathrm{kJ} / \mathrm{mol}$, it is $-110.84 \mathrm{~kJ} / \mathrm{mol}$ when the $\mathrm{CH}_{3} \bullet$ radical reacts with the same thiol, $-54.13 \mathrm{~kJ} / \mathrm{mol}$ when the $\mathrm{C}_{6} \mathrm{H}_{5} \mathrm{CO} \bullet$ radical reacts. Reactions with other thiols have a similar tendency. The fact that the enthalpies of the reactions carried out with T3 and T4 thiols are similar is due to almost the same stability of the sulfur-centered radicals (Table S1). The order of stability for considered thiyl radicals is T2-r $>$ T1-r > T3-r $\approx$ T4-r (Figure S2), causing the reaction enthalpies to have the same order in terms of exothermicity (Table S1). All exothermic reactions can be interpreted as breaking the weak $\mathrm{H}-\mathrm{S}$ sigma bond and forming a relatively stronger $\mathrm{C}-\mathrm{H}$ sigma bond instead.

The stability of the attacking radical has a critical role in both the reaction enthalpies and the size of the activation energies. For example, when the most stable $\mathrm{NC}\left(\mathrm{CH}_{3}\right)_{2} \mathrm{C} \bullet$ radical reacts with the $\mathrm{T} 4$ thiol, the reaction enthalpy is $-15.56 \mathrm{~kJ} / \mathrm{mol}$, and the reaction barrier in Gibbs free energy is 67.72 $\mathrm{kJ} / \mathrm{mol}$. When the most unstable $\mathrm{CH}_{3} \bullet$ radical attacks the same thiol, the reaction enthalpy is $80.49 \mathrm{~kJ} / \mathrm{mol}$, and the reaction barrier in Gibbs free energy is $38.84 \mathrm{~kJ} / \mathrm{mol}$. It is a fact that when the thiol structure changes, the reaction barriers and enthalpies change accordingly. However, it is seen that the barriers of the reactions with the $\mathrm{NC}\left(\mathrm{CH}_{3}\right)_{2} \mathrm{C} \bullet$ radical are larger than $55.00 \mathrm{~kJ} / \mathrm{mol}$, while the barriers in the reactions of other radicals are smaller than $45.00 \mathrm{~kJ} / \mathrm{mol}$. These results show that the radical formed from AIBN performs a much slower hydrogen abstraction reaction than the radicals formed from DMPA. Another remarkable point is that the reaction barrier is significantly reduced when the hydrogen scavenging reaction is carried out with thiophenol. It means that the reaction with the thiol takes place faster than the others. 


\section{Addition Reactions}

The radicals generated from AIBN and DMPA initiators have the potential to react with monomers as a side reaction. The conformational analysis for this reaction of radicals is given in Figure S4. The located activated complex geometries found out from this study are shown in Figures S5-S7, and all reaction energetics and kinetics are given in Tables S2-S4.

Based on the quantum chemically calculated results, the exothermicity of the reactions with the AIBN radical is less than the reactions of the other radicals. Even, it is endergonic for 2-butene and vinyl ether $(1.25 \mathrm{~kJ} / \mathrm{mol}$ and $5.13 \mathrm{~kJ} / \mathrm{mol}$, respectively). All reactions of other radicals $\left(\mathrm{CH}_{3} \bullet\right.$ and $\mathrm{C}_{6} \mathrm{H}_{5} \mathrm{CO} \bullet$ ) are relatively exothermic. For example, when the $\mathrm{CH}_{3} \bullet$ radical is added to vinyl ether, the reaction enthalpy is $-106.42 \mathrm{~kJ} / \mathrm{mol}$, and when $\mathrm{C}_{6} \mathrm{H}_{5} \mathrm{CO} \bullet$ is added to the same monomer, it is $-80.44 \mathrm{~kJ} / \mathrm{mol}$.

It was observed that there was a direct relationship between the stability of the attacking radicals to the monomers and the activation Gibbs energies. The more stable $\mathrm{NC}\left(\mathrm{CH}_{3}\right)_{2} \mathrm{C} \bullet$ radical has higher reaction barriers, while the less stable $\mathrm{CH}_{3} \bullet$ and $\mathrm{C}_{6} \mathrm{H}_{5} \mathrm{CO} \bullet$ radicals have lower activation energies (Table S2). If the reactivity of $\mathrm{CH}_{3} \bullet$ and $\mathrm{C}_{6} \mathrm{H}_{5} \mathrm{CO} \bullet$ radicals are compared among themselves, interestingly, it is seen that the barriers to the reactions of the more unstable $\mathrm{CH}_{3} \bullet$ radical are relatively higher. The SOMO energies of the radicals can explain this. It was calculated 0.28407 Hartree for $\mathrm{CH}_{3} \bullet$, while SOMO energy is relatively higher $\left(-0.26103\right.$ Hartree) for $\mathrm{C}_{6} \mathrm{H}_{5} \mathrm{CO} \bullet$. Therefore, SOMO of $\mathrm{C}_{6} \mathrm{H}_{5} \mathrm{CO} \bullet$ has the potential to more stabilizing the transition state structure by effective interaction with $\Pi^{*}$ orbital of the substrate. In addition, the interaction of the monomer with the $n$ orbitals in the pi bond system of the $\mathrm{C}_{6} \mathrm{H}_{5} \mathrm{CO} \bullet$ radical leads to more stable transition state geometries (Figure S7).

\section{Reaction Kinetics}

In this study, what is expected from a good initiator candidate is that the generated radical should prefer to react with thiol instead of monomer. This preference is presented by a large difference between the rate constants $\left(k_{H A}>>k_{i}\right)$. More favored hydrogen abstraction from thiol can result in more homogeneous thiol-ene polymerization. If there is a competition between these two reactions, the initiator radical reduces the monomer concentration, increasing the heterogeneity of polymerization product. The mentioned rate constants are given in Table 1 , and the logarithms of the ratios of these calculated rate constants, $\log \left(\mathrm{k}_{\mathrm{HA}} / \mathrm{k}_{\mathrm{i}}\right)$, are given in Table 2 .

The addition reaction of alkyl thiyl radicals to electron-deficient monomers occur relatively faster (1,3-butadiene, 2,4-hexadiene, 2,4,6-octatriene, and acrylonitrile) than the electron-rich monomers (2-butene, vinyl chloride, and methyl vinyl ether). If the rate constants of the hydrogen abstraction reactions from thiols are evaluated, it is seen that they are greater than $10^{7} \mathrm{M}^{-1} \cdot \mathrm{s}^{-1}$ for the radicals $\mathrm{CH}_{3} \bullet$ and $\mathrm{C}_{6} \mathrm{H}_{5} \mathrm{CO} \bullet$. When the radical formed from AIBN is used in the hydrogen abstraction reaction, this value is lowered below $10^{5} \mathrm{M}^{-1} \cdot \mathrm{s}^{-1}$.

When the hydrogen abstraction reaction rate is closer to the addition reaction rate for the AIBN, the initiator enhances the side reaction. However, it was calculated that the hydrogen abstraction $\left(1.82 \mathrm{E}+04 \mathrm{M}^{-1} \cdot \mathrm{s}^{-1}\right.$ ) from $\mathrm{C}_{6} \mathrm{H}_{5}-\mathrm{SH}$ by the formed radicals from AIBN occurred faster than other thiols. It means that using the AIBN initiator, the best thiol-ene polymerization is possible with the preference of aromatic thiols. In the case of using the DMPA initiator, better results are obtained as a general tendency of initiators. However, byproduct formation is possible for electron-deficient monomers (1,3-butadiene, 2,4-hexadiene, 2,4,6octatriene, and acrylonitrile) since they have relatively fast addition reactions. Especially for acrylonitrile, the rate constant in the addition reaction with $\mathrm{C}_{6} \mathrm{H}_{5} \mathrm{CO} \bullet$ is very large $\left(1.03 \mathrm{E}+06 \mathrm{M}^{-}\right.$ $\left.{ }^{1} \cdot \mathrm{s}^{-1}\right)$. 
Table 1: Addition $\left(\mathrm{k}_{\mathrm{i}}\right)$ and hydrogen abstraction reaction $\left(\mathrm{K}_{\mathrm{HA}}\right)$ kinetics $\left(\mathrm{M}^{-1} \cdot \mathrm{s}^{-1}\right)$ for $\mathrm{NC}\left(\mathrm{CH}_{3}\right)_{2} \mathrm{C}_{\bullet}, \mathrm{CH}_{3} \bullet$, and $\mathrm{C}_{6} \mathrm{H}_{5} \mathrm{CO} \bullet$ radicals.

\begin{tabular}{|c|c|c|c|}
\hline & $\mathrm{NC}\left(\mathrm{CH}_{3}\right)_{2} \mathrm{C} \bullet$ & $\mathrm{CH}_{3} \bullet$ & $\mathrm{C}_{6} \mathrm{H}_{5} \mathrm{CO} \bullet$ \\
\hline \multicolumn{4}{|c|}{ Addition to monomers $\left(\mathrm{k}_{\mathrm{i}}\right)$} \\
\hline ethylene (1) & $2.57 E-01$ & $1.24 \mathrm{E}+02$ & $4.04 \mathrm{E}+02$ \\
\hline 2-butene (2) & $5.69 \mathrm{E}-02$ & $3.92 \mathrm{E}+00$ & $3.76 \mathrm{E}+02$ \\
\hline 1,3-butadiene (3) & $1.78 \mathrm{E}+02$ & $3.49 \mathrm{E}+04$ & $2.86 \mathrm{E}+04$ \\
\hline 2,4-hexadiene (4) & $6.46 \mathrm{E}+00$ & $2.99 E+02$ & $2.44 \mathrm{E}+04$ \\
\hline 2,4,6-octatriene (5) & $2.20 \mathrm{E}+02$ & $2.16 \mathrm{E}+03$ & $8.22 \mathrm{E}+04$ \\
\hline vinyl chloride (6) & $2.78 \mathrm{E}+00$ & $7.17 \mathrm{E}+02$ & $1.55 \mathrm{E}+03$ \\
\hline acrylonitrile (7) & $6.04 \mathrm{E}+01$ & $4.59 \mathrm{E}+04$ & $1.03 E+06$ \\
\hline methyl vinyl ether (8) & $1.27 \mathrm{E}+00$ & $9.13 \mathrm{E}+00$ & $3.63 E+02$ \\
\hline \multicolumn{4}{|c|}{ Hydrogen abstraction from thiols $\left(\mathrm{k}_{\mathrm{HA}}\right)^{*}$} \\
\hline $\mathrm{T} 1 * *$ & $1.50 \mathrm{E}+02$ & $4.66 \mathrm{E}+07$ & $3.01 \mathrm{E}+08$ \\
\hline T2 & $1.82 \mathrm{E}+04$ & $1.36 \mathrm{E}+08$ & $3.62 \mathrm{E}+08$ \\
\hline T3** & $2.18 \mathrm{E}+03$ & $2.32 \mathrm{E}+07$ & $5.25 \mathrm{E}+07$ \\
\hline T4 & $4.73 E+02$ & $4.41 \mathrm{E}+07$ & $2.37 \mathrm{E}+08$ \\
\hline
\end{tabular}

* Wigner's tunneling correction was performed. ** Reference (21)

The hydrogen abstraction rate constants of $\mathrm{NC}\left(\mathrm{CH}_{3}\right)_{2} \mathrm{C} \bullet$ radical vary between $1.50 \mathrm{E}+02 \mathrm{M}^{-1} \cdot \mathrm{s}^{-1}$ and $1.82 \mathrm{E}+04 \mathrm{M}^{-1} \cdot \mathrm{s}^{-1}$ (Table 1 ). Moreover, rate constants of its addition to alkenes vary between 5.69E-02 $\mathrm{M}^{-1} \cdot \mathrm{s}^{-1}$ (2-butene (2)) and 2.20E+02 M ${ }^{1} \cdot \mathrm{s}^{-1}(2,4,6$-octatriene $(A 5))$. These results show that the rates of the specific reactions are very close to each other when the AIBN initiator is used. Especially in conjugated monomers, such as 1,3butadiene or $2,4,6$-octatriene, the addition reaction rate constants are in the order of $10^{2} \mathrm{M}^{-1} . \mathrm{s}^{-1}$. Therefore, the possibility of desired thiol-ene polymer product cannot be obtained due to this side reaction. Furthermore, an increase in the initiator concentration also leads to an increase in the probability of side reaction. These findings explain why AIBN is not a good initiator for the polymerization. When DMPA is used as the initiator, kinetic data for the hydrogen abstraction rate constants of the radical $\mathrm{CH}_{3} \bullet$ vary between 2.32E+07 $\mathrm{M}^{-1} \cdot \mathrm{s}^{-1}$ and $1.36 \mathrm{E}+08 \mathrm{M}^{-1} \cdot \mathrm{s}^{-1}$ (Table 1 ). For the addition reaction of the same radical, kinetic data changes from $3.92 \mathrm{E}+00 \mathrm{M}^{-1} \cdot \mathrm{s}^{-1}$ (2butene (2)) to $4.59 \mathrm{E}+04 \mathrm{M}^{-1} \cdot \mathrm{s}^{-1}$ (acrylonitrile (7)). The kinetic data addition reaction for the commercial monomers, especially 1,3-butadiene and acrylonitrile, are in the order of $10^{4} \mathrm{M}^{-1} \cdot \mathrm{s}^{-1}$. Compared to the AIBN radical $\left(\mathrm{NC}\left(\mathrm{CH}_{3}\right)_{2} \mathrm{C} \bullet\right)$, a larger difference is obtained between the rate constants. The hydrogen abstraction by the benzoyl $\left(\mathrm{C}_{6} \mathrm{H}_{5} \mathrm{CO} \bullet\right)$ radical, another radical formed from DMPA, is significantly fast and its rate coefficient changes from $5.25 \mathrm{E}+07 \mathrm{M}^{-1} \cdot \mathrm{s}^{-1}$ to $3.62 \mathrm{E}+08 \mathrm{M}^{-1} \cdot \mathrm{s}^{-1}$. As a side reaction, attacking the same radical to the alkenes is relatively slow, and rate coefficients of this reaction change from $3.63 \mathrm{E}+02 \mathrm{M}^{-1} \cdot \mathrm{s}^{-1}$ (methyl vinyl ether) to $1.03 \mathrm{E}+06$ $\mathrm{M}^{-1} \cdot \mathrm{s}^{-1}$ (acrylonitrile). Again, the difference between the rate constants is better compared to the AIBN radical $\left(\mathrm{NC}\left(\mathrm{CH}_{3}\right)_{2} \mathrm{C} \bullet\right)$. Nevertheless, the rate constant of the addition to commercial monomers, especially acrylonitrile, is above the order of $10^{5} \mathrm{M}^{-}$ ${ }^{1} . \mathrm{s}^{-1}$. As a result, electron-poor monomers have a great possibility to give heterogeneous thiol-ene polymerization products with both radicals formed from DMPA. This probability decreases as the initiator concentration decreases, or better results can be obtained without using an initiator.

Table 2 makes kinetic evaluation more understandable and straightforward. The data in the table were obtained by taking the logarithm of the $\mathrm{k}_{\mathrm{HA}} / \mathrm{k}_{\mathrm{i}}$ ratio for the reactions. In this way, it is made visible to what extent the rates of both reactions compete with each other. The $\log \left(\mathrm{k}_{\mathrm{HA}} / \mathrm{k}_{\mathrm{i}}\right)$ data colors were determined according to the following definition; red for values less than two, yellow for values between two and three, and blue for values greater than three. The red color symbolizes that the presence of side reactions is significant, the yellow color symbolizes that the byproduct may show itself, albeit partially, and the blue color symbolizes that the presence of the byproduct is negligible. As a result, it was demonstrated that the AIBN initiator is not a good option for the polymerization since it has a high probability of forming by-products. The applicability of the DMPA initiator for thiol-ene polymerization is well known and has also been proven by quantum chemical calculations. It was predicted that the heterogeneity of the polymerization product resulting from side reactions would increase when initiator concentration is kept high. These findings are also well correlated with a kinetic modeling investigation in the previous literature study (38). 
Table 2: Ratios for the reaction rate constants of hydrogen abstraction from thiols and addition reactions of $\mathrm{NC}\left(\mathrm{CH}_{3}\right)_{2} \mathrm{C} \bullet, \mathrm{CH}_{3} \bullet$, and $\mathrm{C}_{6} \mathrm{H}_{5} \mathrm{CO} \bullet$ radicals to monomers on a logarithmic scale, $\log \left(\mathrm{k}_{\mathrm{HA}} / \mathrm{k}_{\mathrm{i}}\right)$.

\begin{tabular}{|l|cccc|cccc|cccc|}
\hline \multirow{2}{*}{ Monomers } & \multicolumn{3}{|c|}{$\mathrm{NC}\left(\mathrm{CH}_{3}\right)_{2} \mathrm{C} \bullet$} & \multicolumn{5}{c|}{$\mathrm{CH}_{3} \bullet$} & \multicolumn{5}{c|}{$\mathrm{C}_{6} \mathrm{H}_{5} \mathrm{CO} \bullet$} \\
\cline { 2 - 14 } & $\mathrm{T} 1$ & $\mathrm{~T} 2$ & $\mathrm{~T} 3$ & $\mathrm{~T} 4$ & $\mathrm{~T} 1$ & $\mathrm{~T} 2$ & $\mathrm{~T} 3$ & $\mathrm{~T} 4$ & $\mathrm{~T} 1$ & $\mathrm{~T} 2$ & $\mathrm{~T} 3$ & $\mathrm{~T} 4$ \\
\hline ethylene (1) & 2.8 & 4.9 & 3.9 & 3.3 & 5.6 & 6.0 & 5.3 & 5.6 & 5.9 & 6.0 & 5.1 & 5.8 \\
2-butene (2) & 3.4 & 5.5 & 4.6 & 3.9 & 7.1 & 7.5 & 6.8 & 7.1 & 5.9 & 6.0 & 5.1 & 5.8 \\
1,3-butadiene (3) & -0.1 & 2.0 & 1.1 & 0.4 & 3.1 & 3.6 & 2.8 & 3.1 & 4.0 & 4.1 & 3.3 & 3.9 \\
2,4-hexadiene (4) & 1.4 & 3.4 & 2.5 & 1.9 & 5.2 & 5.7 & 4.9 & 5.2 & 4.1 & 4.2 & 3.3 & 4.0 \\
2,4,6-octatriene (5) & -0.2 & 1.9 & 1.0 & 0.3 & 4.3 & 4.8 & 4.0 & 4.3 & 3.6 & 3.6 & 2.8 & 3.5 \\
vinyl chloride (6) & 1.7 & 3.8 & 2.9 & 2.2 & 4.8 & 5.3 & 4.5 & 4.8 & 5.3 & 5.4 & 4.5 & 5.2 \\
acrylonitrile (7) & 0.4 & 2.5 & 1.6 & 0.9 & 3.0 & 3.5 & 2.7 & 3.0 & 2.5 & 2.5 & 1.7 & 2.4 \\
methyl vinyl ether (8) & 2.1 & 4.2 & 3.2 & 2.6 & 6.7 & 7.2 & 6.4 & 6.7 & 5.9 & 6.0 & 5.2 & 5.8 \\
\hline
\end{tabular}

The colored values defined as red is $x<2$, yellow is $2<x<3$, and blue is $x>3\left(x=k_{H A} / k_{i}\right)$.

\section{CONCLUSION}

This comprehensive quantum chemical study demonstrates the importance of initiator selection for thiol-ene polymerization. It was found out that aromatic thiols (such as thiophenol) were more prone to thiol-ene polymerization when AIBN is preferred as the initiator. Best results with this combination were obtained with 2-butene and methyl vinyl ether. Regardless of the type of initiator, 2-butene has a high affinity for the thiolene reaction. It is worth noting that initiators have a high tendency to initiate classical radical polymerization as a side polymerization with electron-deficient or conjugated monomers. As a general assessment, the performance of AIBN is not satisfactory compared to the application of DMPA.

Radicals formed from DMPA have been found to initiate the thiol-ene reaction without any problems, regardless of the thiol structure, except for electron-poor or conjugated monomers. Especially 2-butene, vinyl chloride, methyl vinyl ether have a low tendency to give by-products with this initiator. Even conjugated 2,4-hexadiene monomer can effectively initiate thiol-ene reaction instead of classical radical polymerization initiation. Another finding is that the $\mathrm{C}_{6} \mathrm{H}_{5} \mathrm{CO} \bullet$ radical is more likely to form by-products than the $\mathrm{CH}_{3} \bullet$ radical for the DMPA initiator. In any case, it was calculated that radicals formed from DMPA had a lower tendency to side-reactions than radicals formed from AIBN.

It is worth noting that these results only provide some information about the initiation step of the thiol-ene polymerization. A good initiation does not always mean that it results in a good polymerization; other reactions in the thiol-ene polymerization mechanism, such as propagation and chain transfer, strongly depend on the chemical structures of monomers and thiols, as mentioned in the introduction. On the other hand, a poor initiation performance always results in a heterogeneous product.

\section{ACKNOWLEDGMENTS}

I am thankful for CPU usage and funding to the Scientific and Technological Research Council of Turkey (TUBITAK, Project Number: 217Z073). TUBITAK ULAKBIM, High Performance and Grid Computing Center (TRUBA resources) partially provided computing resources used in this work.

\section{REFERENCES}

1. Griesbaum K. Problems and Possibilities of the FreeRadical Addition of Thiols to Unsaturated Compounds. Angew Chem Int Ed Engl. 1970 Apr;9(4):273-87. $\leq \mathrm{DOI}>$.

2. Dondoni A. The Emergence of Thiol-Ene Coupling as a Click Process for Materials and Bioorganic Chemistry. Angew Chem Int Ed. 2008 Nov 10;47(47):8995-7. $\leq \mathrm{DOI}>$.

3. Hoyle CE, Bowman CN. Thiol-Ene Click Chemistry. Angewandte Chemie International Edition. 2010 Feb 22;49(9):1540-73. <DOI $>$.

4. Hoyle CE, Lowe AB, Bowman CN. Thiol-click chemistry: a multifaceted toolbox for small molecule and polymer synthesis. Chem Soc Rev. 2010;39(4):1355-87. <DOI>.

5. Jacobine A, Fouassier J, Rabek J. Radiation curing in polymer science and technology. vol III, Elsevier (London). 1993; 
6. Sun Y, Gao Y, Zhou L, Huang J, Fang H, Ma H, et al. A Study on the Electro-Optical Properties of Thiol-Ene Polymer Dispersed Cholesteric Liquid Crystal (PDChLC) Films. Molecules. 2017 Feb 22;22(2):317. <DOI>.

7. Heidecke $C D$, Lindhorst TK. Iterative Synthesis of Spacered Glycodendrons as Oligomannoside Mimetics and Evaluation of Their Antiadhesive Properties. Chem Eur J. 2007 Nov 5;13(32):9056-67. <DOI .

8. Chen G, Amajjahe S, Stenzel MH. Synthesis of thiollinked neoglycopolymers and thermo-responsive glycomicelles as potential drug carrier. Chem Commun. 2009;(10):1198-200. <DOI>.

9. Natali M, Begolo S, Carofiglio T, Mistura G. Rapid prototyping of multilayer thiolene microfluidic chips by photopolymerization and transfer lamination. Lab Chip. 2008;8(3):492-4. <DOI .

10. Cabral JT, Hudson SD, Harrison C, Douglas JF. Frontal Photopolymerization for Microfluidic Applications. Langmuir. 2004 Nov 1;20(23):10020-9. <DOI.

11. Cygan ZT, Cabral JT, Beers KL, Amis EJ. Microfluidic Platform for the Generation of Organic-Phase Microreactors. Langmuir. 2005 Apr 1;21(8):3629-34. $\leq$ DOI $>$.

12. Cramer NB, Reddy SK, O'Brien AK, Bowman CN. Thiol-Ene Photopolymerization Mechanism and Rate Limiting Step Changes for Various Vinyl Functional Group Chemistries. Macromolecules. 2003 Oct 1;36(21):79649. $\leq \mathrm{DOI}>$.

13. Zgrzeba A, Andrzejewska E, Marcinkowska A. Ionic liquid - containing ionogels by thiol-ene photopolymerization. Kinetics and solvent effect. RSC Adv. 2015;5(121):100354-61. <DOI .

14. Marcinkowska A, Zgrzeba A, Lota G, Kopczyński K, Andrzejewska E. Ionogels by thiol-ene photopolymerization in ionic liquids: Formation, morphology and properties. Polymer. 2019 Jan;160:27281. $\leq \mathrm{DOI}>$.

15. Munar I, Fındık V, Degirmenci I, Aviyente V. Solvent Effects on Thiol-Ene Kinetics and Reactivity of Carbon and Sulfur Radicals. J Phys Chem A. 2020 Apr 2;124(13):2580-90. <DOI $>$.

16. Northrop BH, Coffey RN. Thiol-Ene Click Chemistry: Computational and Kinetic Analysis of the Influence of Alkene Functionality. J Am Chem Soc. 2012 Aug $22 ; 134(33): 13804-17$. $\leq \mathrm{DOI}>$.

17. Fındık V, Degirmenci I, Çatak Ş, Aviyente V. Theoretical investigation of thiol-ene click reactions: A DFT perspective. European Polymer Journal. 2019 Jan;110:211-20. <DOI $>$.

18. Long $\mathrm{KF}$, Bongiardina $\mathrm{NJ}$, Mayordomo $\mathrm{P}$, Olin $\mathrm{MJ}$, Ortega AD, Bowman CN. Effects of $1^{\circ}, 2^{\circ}$, and $3^{\circ}$ Thiols on Thiol-Ene Reactions: Polymerization Kinetics and Mechanical Behavior. Macromolecules. $2020 \mathrm{Jul}$ 28;53(14):5805-15. <DOI $>$.
19. Coote ML, Degirmenci I. Theory and Applications of Thiyl Radicals in Polymer Chemistry. In: Computational Quantum Chemistry [Internet]. Elsevier; 2019 [cited 2021 Dec 29]. p. 195-218. ISBN: 978-0-12-815983-5. $\leq \mathrm{URL}>$.

20. Hafeez S, Khatri V, Kashyap HK, Nebhani L. Computational and experimental approach to evaluate the effect of initiator concentration, solvents, and enes on the TEMPO driven thiol-ene reaction. New J Chem.

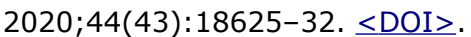

21. Degirmenci I. Effect of Initiator Structure on ThiolEne Polymerization: A DFT Study. Macromol Theory Simul. 2021 Sep;2100040. <DOI $>$.

22. Koo SPS, Stamenović MM, Prasath RA, Inglis $A J, D u$ Prez FE, Barner-Kowollik C, et al. Limitations of radical thiol-ene reactions for polymer-polymer conjugation. J Polym Sci A Polym Chem. 2010 Apr 15;48(8):1699-713. $<$ DOI $>$.

23. Frisch M, Trucks G, Schlegel H, Scuseria G, Robb M, Cheeseman J et al. Gaussian 16 Rev. B. 01. Gaussian, Inc., Wallingford, CT; 2016.

24. Zhao Y, Truhlar DG. The M06 suite of density functionals for main group thermochemistry, thermochemical kinetics, noncovalent interactions, excited states, and transition elements: two new functionals and systematic testing of four M06-class functionals and 12 other functionals. Theor Chem Account. 2008 May;120(1-3):215-41. <DOI $>$.

25. Furuncuoğlu T, Uğur İ, Değirmenci İ, Aviyente V. Role of Chain Transfer Agents in Free Radical Polymerization Kinetics. Macromolecules. 2010 Feb 23;43(4):1823-35. $\leq \mathrm{DOI}>$.

26. Truong TN, Truhlar DG. Ab initio transition state theory calculations of the reaction rate for $\mathrm{OH}+\mathrm{CH} 4 \rightarrow \mathrm{H}$ $2 \mathrm{O}+\mathrm{CH}$ 3. The Journal of Chemical Physics. 1990 Aug;93(3):1761-9. <DOI $>$.

27. Duan $X$, Scheiner S. Energetics, proton transfer rates, and kinetic isotope effects in bent hydrogen bonds. Journal of the American Chemical Society. 1992;114(14):5849-56. ISSN: 0002-7863.

28. Griller D, Ingold KU. Persistent carbon-centered radicals. Accounts of Chemical Research. 1976;9(1):139. ISSN: 0001-4842.

29. Coote $M L$, Lin CY, Beckwith ALJ, Zavitsas AA. A comparison of methods for measuring relative radical stabilities of carbon-centred radicals. Phys Chem Chem Phys. 2010;12(33):9597. <DOI>.

30. Posner T. Beiträge zur Kenntniss der ungesättigten Verbindungen. II. Ueber die Addition von Mercaptanen an ungesättigte Kohlenwasserstoffe. Ber Dtsch Chem Ges. $1905 ; 38(1): 646-57$.

31. Hoyle CE, Lee TY, Roper T. Thiol-enes: Chemistry of the past with promise for the future. J Polym Sci A Polym Chem. 2004 Nov 1;42(21):5301-38. <DOI>. 
32. Chiou B-S, English RJ, Khan SA. Rheology and PhotoCross-Linking of Thiol-Ene Polymers. Macromolecules. 1996 Jan 1;29(16):5368-74. <DOI>.

33. Hoyle CE, Hensel RD, Grubb MB. Temperature dependence of the laser-initiated polymerization of a thiol-ene system. J Polym Sci Polym Chem Ed. 1984 Aug;22(8):1865-73. <DOI $>$.

34. Cramer NB, Bowman CN. Kinetics of thiol-ene and thiol-acrylate photopolymerizations with real-time fourier transform infrared. J Polym Sci A Polym Chem. 2001 Oct 1;39(19):3311-9. <DOI .

35. Cramer NB, Scott JP, Bowman CN. Photopolymerizations of Thiol-Ene Polymers without Photoinitiators. Macromolecules. 2002 Jul $1 ; 35(14): 5361-5 . \leq \mathrm{DOI}>$.
36. Cramer NB, Davies $\mathrm{T}$, O'Brien AK, Bowman CN. Mechanism and Modeling of a Thiol-Ene Photopolymerization. Macromolecules. 2003 Jun $1 ; 36(12): 4631-6 . \leq \mathrm{DOI}>$.

37. Uygun M, Tasdelen MA, Yagci Y. Influence of Type of Initiation on Thiol-Ene "Click" Chemistry: Influence of Type of Initiation on Thiol-Ene "Click" Chemistry. Macromol Chem Phys. 2010 Jan 5;211(1):103-10. $\leq \mathrm{DOI}>$.

38. Derboven $P, D^{\prime}$ hooge $D R$, Stamenovic MM, Espeel $P$, Marin GB, Du Prez FE, et al. Kinetic Modeling of Radical Thiol-Ene Chemistry for Macromolecular Design: Importance of Side Reactions and Diffusional Limitations. Macromolecules. 2013 Mar 12;46(5):1732-42. <DOI>.

39. Mucci V, Vallo C. Efficiency of 2,2-dimethoxy-2phenylacetophenone for the photopolymerization of methacrylate monomers in thick sections. J Appl Polym Sci. 2012 Jan 5;123(1):418-25. <DOI $>$. 


\title{
Role of Initiator Structure on Thiol-Ene Polymerization: A
} Comprehensive Theoretical Study

\author{
Isa Degirmenci \\ Chemical Engineering Department, Ondokuz Mayıs University, 55139 Samsun, Turkey \\ E-mail: isa.degirmenci@omu.edu.tr
}




\section{$\mathrm{NC}\left(\mathrm{CH}_{3}\right)_{2} \mathrm{C} \bullet$}

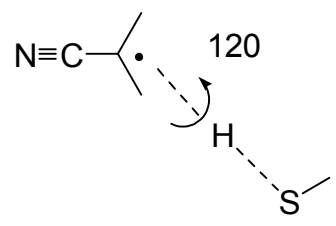

T1

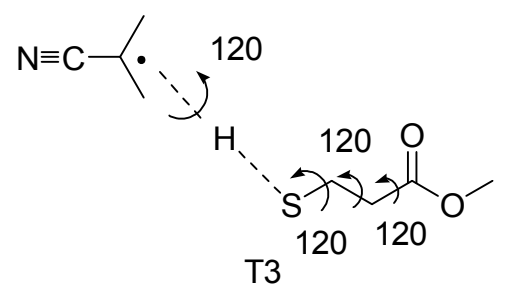<smiles>CC(C#N)=CCSc1ccccc1</smiles>

T2

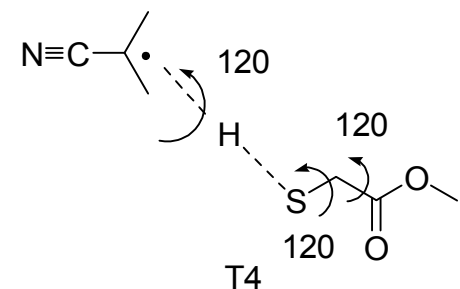

T4

\section{$\mathrm{CH}_{3} \bullet$}

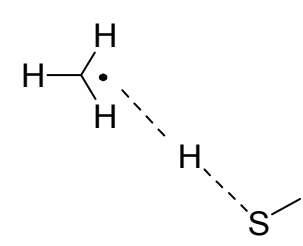

$\mathrm{T} 1$

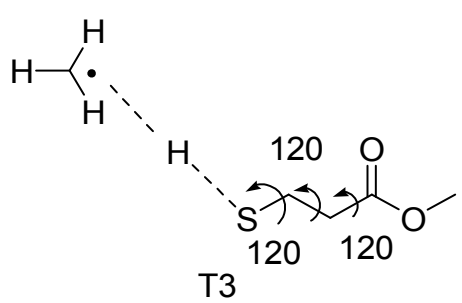<smiles>CCSc1ccccc1</smiles>

T2

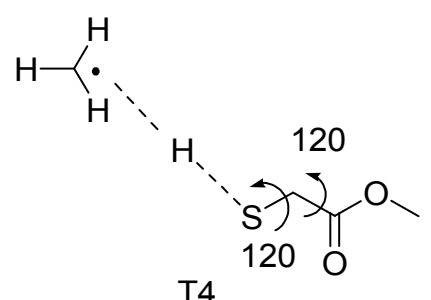

T4

\section{$\mathrm{C}_{6} \mathrm{H}_{5} \mathrm{CO} \bullet$}

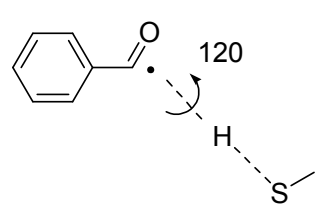

T1

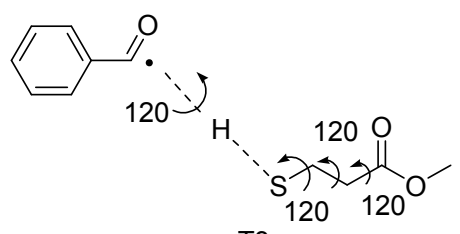

T3

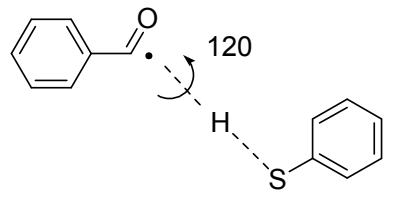

T2

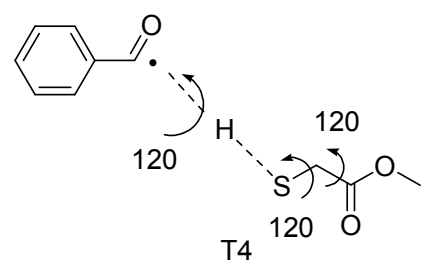

Figure S1: Schematic representation of conformational analysis at the transition states for hydrogen abstraction reaction of $\mathrm{NC}\left(\mathrm{CH}_{3}\right)_{2} \mathrm{C} \bullet, \mathrm{CH}_{3} \bullet$, and $\mathrm{C}_{6} \mathrm{H}_{5} \mathrm{CO} \bullet$ radicals from $\mathrm{T} 1, \mathrm{~T} 2, \mathrm{~T} 3$, and $\mathrm{T} 4$ thiols. 
Table S1: Energetics $(\mathrm{kJ} / \mathrm{mol})$ and kinetics $\left(\mathrm{L} . \mathrm{mol}^{-1} \cdot \mathrm{s}^{-1}\right)$ for the hydrogen abstraction reaction from T1, $\mathrm{T} 2, \mathrm{~T} 3$, and $\mathrm{T} 4$ thiols by $\mathrm{NC}\left(\mathrm{CH}_{3}\right)_{2} \mathrm{C} \bullet, \mathrm{CH}_{3} \bullet$, and $\mathrm{C}_{6} \mathrm{H}_{5} \mathrm{CO} \bullet$ radicals.

$\begin{array}{cccccc} & \text { Thiol } & \Delta \mathrm{H}_{\mathrm{rxn}} & \Delta \mathrm{G}_{\mathrm{rxn}} & \Delta \mathrm{H}^{\ddagger} & \mathrm{DG}^{\ddagger} \\ \mathrm{NC}\left(\mathrm{CH}_{3}\right)_{2} \mathrm{C} \bullet & -21.72 & -13.57 & 21.66 & 70.67 \\ & \mathrm{~T} 1 & -45.90 & -35.92 & 3.87 & 58.61 \\ & \mathrm{~T} 2 & -15.57 & -9.88 & 8.25 & 64.11 \\ & \mathrm{~T} 3 & -15.56 & -8.20 & 11.10 & 67.72 \\ \mathrm{CH}_{3} \bullet & \mathrm{T} 4 & -86.66 & -81.28 & 2.84 & 38.77 \\ & \mathrm{~T} 1 & -110.84 & -103.63 & -2.29 & 35.85 \\ & \mathrm{~T} 2 & -80.51 & -77.59 & 1.18 & 40.41 \\ & \mathrm{~T} 3 & -80.49 & -75.91 & -2.50 & 38.84 \\ \mathrm{C}_{6} \mathrm{H}_{5} \mathrm{CO} ・ & \mathrm{~T} 4 & -29.95 & -27.20 & -2.42 & 33.96 \\ & \mathrm{~T} 1 & -54.13 & -49.55 & -14.41 & 33.29 \\ & \mathrm{~T} 2 & -23.80 & -23.51 & -15.02 & 38.14 \\ & \mathrm{~T} 3 & -23.78 & -21.83 & -16.59 & 34.55\end{array}$


Thiols

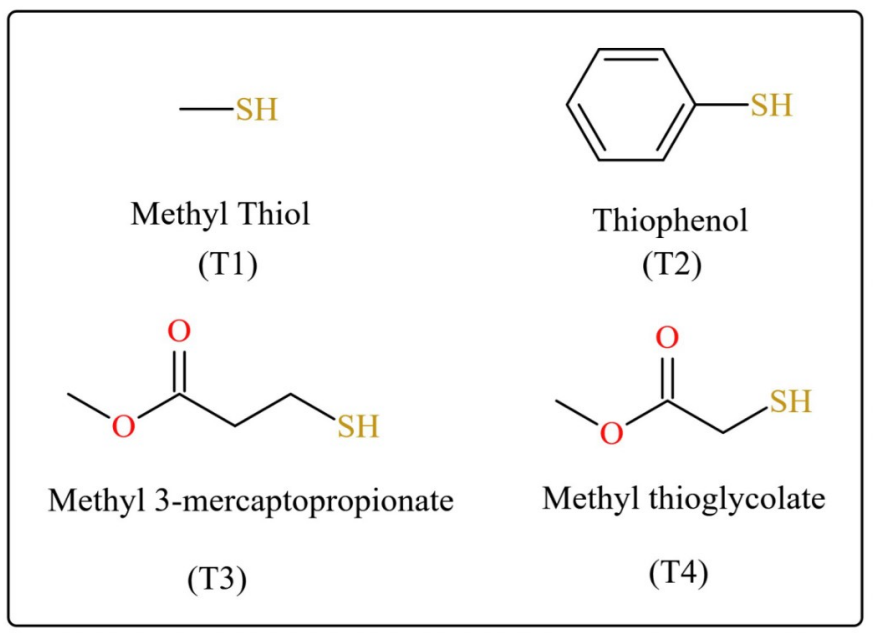

Thiyl Radicals

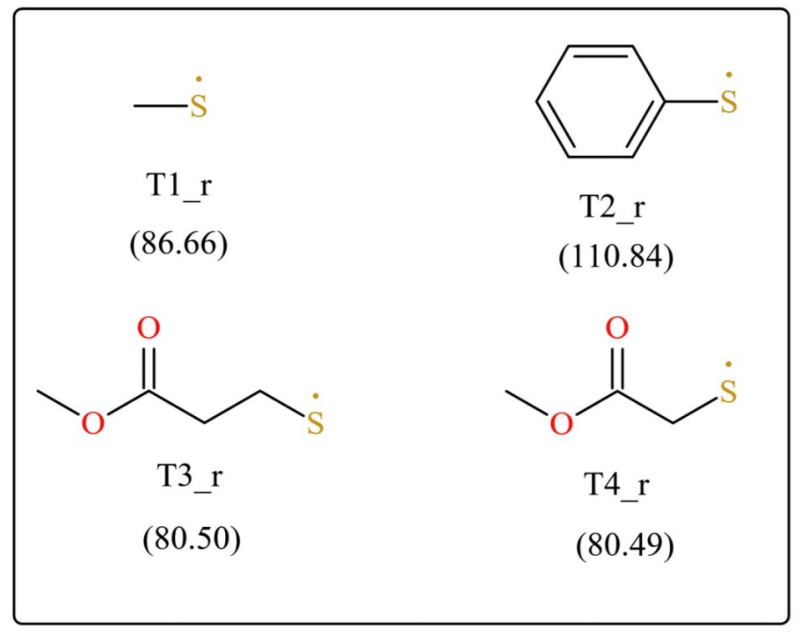

Figure S2: Chemical strucutres of thiols, formed thiyl radicals form the considered thiols and their radical stabilisation energies (RSE) in $\mathrm{kJ} / \mathrm{mol}$. 


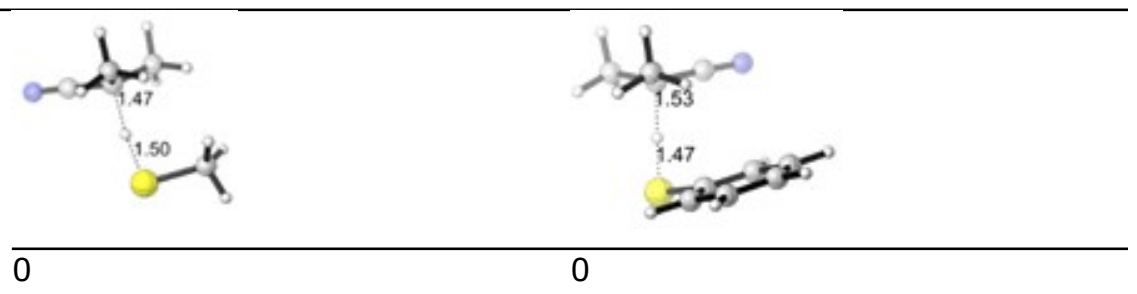

$\mathrm{NC}\left(\mathrm{CH}_{3}\right)_{2} \mathrm{C} \bullet$

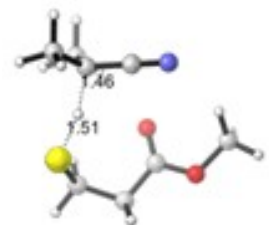

0

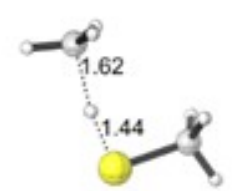

0

$\mathrm{CH}_{3} \bullet$

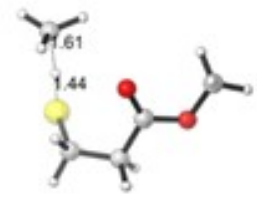

0

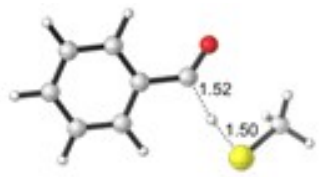

$\mathrm{C}_{6} \mathrm{H}_{5} \mathrm{CO} \bullet$

0

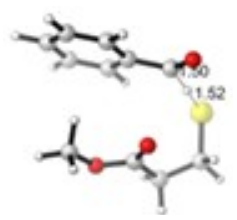

0

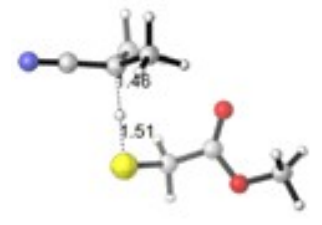

0

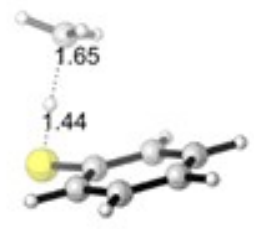

0

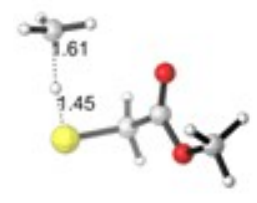

0

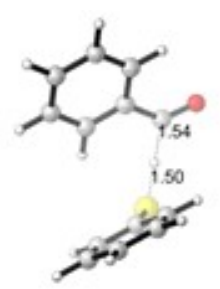

0

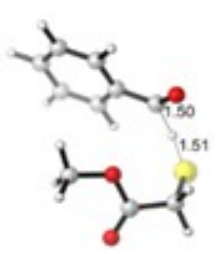

0

Figure S3: Hydrogen abstraction transition state geometries of $\mathrm{NC}\left(\mathrm{CH}_{3}\right)_{2} \mathrm{C} \bullet, \mathrm{CH}_{3} \bullet$, and $\mathrm{C}_{6} \mathrm{H}_{5} \mathrm{CO} \bullet$ radicals from $\mathrm{T} 1, \mathrm{~T} 2, \mathrm{~T} 3$, and $\mathrm{T} 4$ thiols. 